\title{
Long-term prognosis of patients with acute myocardial infarction due to unprotected left main coronary artery disease: a single-centre experience over 14 years
}

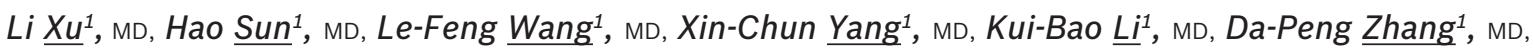
Hong-Shi Wang ${ }^{1}$, MD, Wei-Ming $\underline{L i}^{1}, \mathrm{MD}$

\begin{abstract}
INTRODUCTION Acute myocardial infarction (AMI) due to unprotected left main coronary artery (ULMCA) disease is clinically catastrophic although it has a low incidence. Studies on the long-term prognosis of these patients are rare. METHODS From January 1999 to September 2013, 55 patients whose infarct-related artery was the ULMCA were enrolled. Clinical, angiographic and interventional data was collected. Short-term and long-term clinical follow-up results as well as prognostic determinants during hospitalisation and follow-up were analysed.

RESULTS Cardiogenic shock (CS) occurred in 30 (54.5\%) patients. During hospitalisation, 22 (40.0\%) patients died. Multivariate logistic regression analysis showed that CS (odds ratio [OR] 5.86; $p=0.03$ ), collateral circulation of Grade 2 or 3 (OR 0.14; $p=0.02$ ) and final flow of thrombolysis in myocardial infarction (TIMI) Grade 3 (OR 0.05; $p=0.03$ ) correlated with death during hospitalisation. 33 patients survived to discharge; another seven patients died during the follow-up period of $44.6 \pm 31.3$ (median 60 , range $0.67-117.00$ ) months. The overall mortality rate was $52.7 \%(n=29$ ). Kaplan-Meier analysis showed that the total cumulative survival rate was $30.7 \%$. Cox multivariate regression analysis showed that CS during hospitalisation was the only predictor of overall mortality (hazard ratio $4.07,95 \%$ confidence interval 1.40-11.83; $p=0.01$ ).

CONCLUSION AMI caused by ULMCA lesions is complicated by high incidence of CS and mortality. CS, poor collateral blood flow and failure to restore final flow of TIMI Grade 3 correlated with death during hospitalisation. CS is the only predictor of long-term overall mortality.
\end{abstract}

Keywords: acute myocardial infarction, cardiogenic shock, infarct-related artery, percutaneous coronary intervention, unprotected left main coronary artery

\section{INTRODUCTION}

Acute myocardial infarction (AMI) due to unprotected left main coronary artery (ULMCA) disease is clinically catastrophic although it has a low incidence. Due to the high likelihood of cardiogenic shock (CS) as a complication, patients with AMI due to ULMCA disease have a high mortality rate even after successful revascularisation. ${ }^{(1-5)}$ Studies on the prognosis of these patients, especially in the long term, are rare. In addition, follow-up durations reported in previous published research were short and therefore cannot show the long-term prognosis of these patients. ${ }^{(4-6)}$ In the present study, we analysed the short- and long-term prognoses of patients with AMI due to ULMCA disease as well as the predictors of these prognoses. Only AMI patients whose infarct-related artery (IRA) was the ULMCA, as confirmed by angiography, were enrolled and long-term follow-up was performed.

\section{METHODS}

From January 1999 to September 2013, 5,578 patients in Beijing Chaoyang Hospital, Capital Medical University, Beijing, China, received emergency coronary angiography; patients whose IRA was confirmed to be the ULMCA were enrolled in this study. Clinical, angiographic and interventional characteristics as well as short- and long-term clinical follow-up results were analysed.
The diagnosis of AMI requires detection of a rise and fall of cardiac biomarker values (e.g. cardiac troponin), symptoms of ischaemia and changes on electrocardiography. ${ }^{(7)}$ Coronary flow in the IRA before and after revascularisation was graded according to the classification system of the thrombolysis in myocardial infarction (TIMI) study group. ${ }^{(8)}$ Collateral flow was graded using a classification system developed by Rentrop et al. ${ }^{(9)}$ ULMCA disease was defined as a lesion $\geq 50 \%$ in the left main artery in the absence of a patent coronary artery bypass graft (CABG) to the left anterior descending (LAD) or circumflex arteries. ${ }^{(10,11)} \mathrm{CS}$ was defined as hypotension secondary to cardiac dysfunction (i.e. systolic blood pressure of $<90 \mathrm{mmHg}$ for at least 30 minutes or the need for supportive measures to maintain a systolic blood pressure of $\geq 90 \mathrm{mmHg}$ ) and end-organ hypoperfusion. ${ }^{(12)}$ The endpoint of the study was set as all-cause mortality. Patients and their families were followed-up via telephone interviews, and outpatient and inpatient medical records were collected. Patients were divided into two groups depending on whether death occurred during hospitalisation or follow-up; predictors of death during hospitalisation and long-term follow-up were analysed.

Data analysis was performed using SPSS Statistics version 17.0 (SPSS Inc, Chicago, IL, USA). Continuous data was expressed as mean \pm standard deviation, while discrete data was expressed as percentages. Student's $t$-test and chi-square test (Fisher's

${ }^{1}$ Heart Center, Beijing Chaoyang Hospital, Capital Medical University, Beijing, China

Correspondence: Dr Le-Feng Wang, Consultant, Heart Center, Beijing Chaoyang Hospital, Capital Medical University, No. 8, Gongtinan Road, Chaoyang District, Beijing 100020, China.drheart@aliyun.com 
exact test when necessary) were used to analyse continuous and discrete data, respectively. Logistic regression analysis was used to analyse factors associated with death during hospitalisation. Cox regression analysis was performed to analyse the risk factors of death during follow-up; univariate analysis was conducted and statistically significant factors were then included in multivariate analysis. Kaplan-Meier analysis was used to estimate the cumulative survival rate. Statistical significance was set at $\mathrm{p}<0.05$ in a two-sided test.

\section{RESULTS}

A total of 55 patients were included in the study. Their mean age was $61.3 \pm 11.4$ (range $41-86$ ) years and 49 patients were male. $47(85.5 \%)$ patients had an acute, extensive, anterior wall ST-segment elevation myocardial infarction (STEMI) and the remaining $8(14.5 \%)$ had acute non-ST-segment elevation myocardial infarction (NSTEMI). There were five cases of stent thrombosis in the left main coronary artery (LMCA), including two cases of subacute stent thrombosis, two cases of late stent thrombosis and one case of very late stent thrombosis. Of the two patients with subacute stent thrombosis, one had a history of CABG with occluded bypass graft. CS occurred in 30 (54.5\%) patients. Among the remaining 25 patients, there were ten cases of Killip class III, eight cases of Killip class II and seven cases of Killip class I. Echocardiography was not performed in ten patients before they died; in the other 45 patients, postoperative echocardiography showed a mean left ventricular ejection fraction (LVEF) of $49.0 \% \pm 10.8 \%$ (range $24.0 \%-70.0 \%$ ) (Table I).

All patients had a dominant right coronary artery. 51 patients underwent emergency percutaneous coronary intervention $(\mathrm{PCl})$, with a mean door-to-balloon time of $110.8 \pm 37.1$ (range 57-300) minutes. Of the 51 patients, 45 received stent implantation and six received only balloon angioplasty, including three cases of elective CABG after emergency $\mathrm{PCl}$. In the patients who received stent implantation, the stent covered the LAD and LMCA in 39 cases. In two cases, the attempt to open the LAD failed, and the stent covered the circumflex artery and LMCA; in the remaining four cases, double stent procedure was performed for bifurcation lesions. Emergency CABG was performed directly in one patient; in another, self-recanalisation occurred and elective CABG was performed two weeks after emergency angiography. Another two patients died soon after receiving emergency coronary angiography and revascularisation could not occur. 52 patients $(94.5 \%)$ received intra-aortic balloon pump (IABP) implantation (Table II).

A total of $22(40.0 \%)$ patients died in hospital: five patients died during angiography or $\mathrm{PCl}$ and the remaining 17 died within $3.0 \pm 4.5$ (range 1-21) days after onset of AMI. In all cases, the primary cause of death was refractory CS. One patient suffered from subacute stent thrombosis 11 days after primary $\mathrm{PCl}$ and died two days after the second $\mathrm{PCl}$, which was balloon angioplasty. Multivariate logistic regression analysis revealed that the incidence of CS during hospitalisation (odds ratio [OR] 5.86), collateral circulation of Grade 2 or 3 (OR 0.14 ) and final flow of TIMI Grade 3 (OR 0.05) correlated with mortality during hospitalisation (Table III). The surviving 33 patients were discharged $18.9 \pm 10.1$ (range 6-50) days after admission. Long-term follow-up of $44.6 \pm 31.3$ (median 60, range $0.67-117.00)$ months was performed. 28 (84.8\%) patients received follow-up over one year and 20 (60.6\%) patients received follow-up over three years. During the follow-up, another $7(21.2 \%)$ patients died, making the overall mortality rate $52.7 \%(n=29)$. The total cumulative survival rate was $30.7 \%$, as estimated via Kaplan-Meier analysis (Fig. 1).

Table I. Baseline clinical characteristics of the patients.

\begin{tabular}{|c|c|c|c|c|}
\hline \multirow[t]{2}{*}{ Parameter } & \multicolumn{3}{|c|}{ No. (\%) } & \multirow[t]{2}{*}{ p-value } \\
\hline & $\begin{array}{c}\text { Total } \\
(n=55)\end{array}$ & $\begin{array}{c}\text { Survived } \\
\text { hospitalisation }(n=33)\end{array}$ & $\begin{array}{c}\text { Did not survive } \\
\text { hospitalisation }(n=22)\end{array}$ & \\
\hline Male gender & $49(89.1)$ & $29(87.9)$ & $20(90.9)$ & 1.00 \\
\hline Age* $^{*}(y r)$ & $61.3 \pm 11.4$ & $59.1 \pm 11.4$ & $64.5 \pm 11.0$ & 0.08 \\
\hline Diagnosis of NSTEMI & $8(14.5)$ & $6(18.2)$ & $2(9.1)$ & 0.45 \\
\hline CPR before angiography & $9(16.4)$ & $5(15.2)$ & $4(18.2)$ & 1.00 \\
\hline Cardiogenic shock & $30(54.5)$ & $11(33.3)$ & $19(86.4)$ & $<0.001$ \\
\hline Hypertension & $26(47.3)$ & $19(57.6)$ & $7(31.8)$ & 0.10 \\
\hline Diabetes mellitus & $7(12.7)$ & $4(12.1)$ & $3(13.6)$ & 1.00 \\
\hline Hyperlipidaemia & $8(14.5)$ & $6(18.2)$ & $2(9.1)$ & 0.45 \\
\hline Smoking & $44(80.0)$ & $28(84.8)$ & $16(72.7)$ & 0.32 \\
\hline \multicolumn{5}{|l|}{ On admission } \\
\hline Creatinine $>133 \mu \mathrm{mol} / \mathrm{L}$ & $18(32.7)$ & $8(24.2)$ & $10(45.5)$ & 0.14 \\
\hline $\mathrm{pH}$ value ${ }^{*,+}(n=49)$ & $7.29 \pm 0.14$ & $7.29 \pm 0.15$ & $7.28 \pm 0.13$ & 0.72 \\
\hline $\operatorname{LVEF}^{* \neq \neq}(n=45)$ & $49.0 \pm 10.8$ & $50.4 \pm 10.6$ & $45.3 \pm 10.9$ & 0.08 \\
\hline \multicolumn{5}{|l|}{ Medication } \\
\hline New oral P2Y12 inhibitor (ticagrelor) & $3(5.5)$ & $2(6.1)$ & $1(4.5)$ & 0.91 \\
\hline Glycoprotein Ilb/IIla inhibitor & $33(60.0)$ & $21(63.6)$ & $12(54.5)$ & 0.58 \\
\hline
\end{tabular}

* Data presented as mean \pm standard deviation. $\$ 6$ patients died before they could undergo blood gas analysis. $¥ 10$ patients died before they could undergo echocardiography. CPR: cardiopulmonary resuscitation; LVEF: left ventricular ejection fraction; NSTEMI: non-ST-segment elevation myocardial infarction 
Table II. Angiographic and interventional data of the patients.

\begin{tabular}{|c|c|c|c|c|}
\hline \multirow[t]{2}{*}{ Parameter } & \multicolumn{3}{|c|}{ No. (\%) } & \multirow[t]{2}{*}{ p-value } \\
\hline & $\begin{array}{c}\text { Total } \\
(n=55)\end{array}$ & $\begin{array}{c}\text { Survived } \\
\text { hospitalisation }(n=33)\end{array}$ & $\begin{array}{c}\text { Did not survive } \\
\text { hospitalisation }(n=22)\end{array}$ & \\
\hline Door-to-balloon time* (min) & $110.8 \pm 37.1$ & $114.5 \pm 51.9$ & $108.7 \pm 26.6$ & 0.60 \\
\hline RCA stenosis > $70 \%$ & $25(45.5)$ & $13(39.4)$ & $12(54.5)$ & 0.29 \\
\hline Self-recanalisation TIMI Grade 2/3 & $15(27.3)$ & $12(36.4)$ & $3(13.6)$ & 0.07 \\
\hline Collateral circulation Grade 2/3 & $25(45.5)$ & $21(63.6)$ & $4(18.2)$ & 0.001 \\
\hline $\mathrm{PCl}$ after emergency angiography & $51(92.7)$ & $32(97.0)$ & $19(86.4)$ & 0.29 \\
\hline Thrombus aspiration & $15(27.3)$ & $11(33.3)$ & $4(18.2)$ & 0.35 \\
\hline Stent implantation & $45(81.8)$ & $29(87.9)$ & $16(72.7)$ & 0.18 \\
\hline Final flow TIMI Grade 3 & $46(83.6)$ & $32(97.0)$ & $14(63.6)$ & 0.002 \\
\hline
\end{tabular}

*Data presented as mean \pm standard deviation. $\mathrm{PCI}$ : percutaneous coronary intervention; RCA: right coronary artery; TIMI: thrombolysis in myocardial infarction

Table III. Predictors of mortality during hospitalisation.

\begin{tabular}{lccc}
\hline Parameter & OR & $\mathbf{9 5 \% ~ C l ~}$ & p-value \\
\hline Collateral circulation Grade 2/3 & 0.14 & $0.03-0.77$ & 0.02 \\
Final flow TIMI Grade 3 & 0.05 & $0.03-0.69$ & 0.03 \\
Cardiogenic shock & 5.86 & $1.22-28.25$ & 0.03 \\
\hline
\end{tabular}

$\mathrm{Cl}$ : confidence interval; OR: odds ratio; TIMI: thrombolysis in myocardial infarction

Table IV. Cox regression analysis of the predictors of total mortality.

\begin{tabular}{lccc}
\hline Parameter & HR & 95\% CI & p-value \\
\hline Univariate Cox & & & \\
Age $\geq 60$ yr & 2.27 & $1.05-4.92$ & 0.04 \\
$\quad$ Collateral circulation & 0.29 & $0.13-0.65$ & 0.003 \\
Grade 2/3 & & & \\
Final flow TIMI Level 3 & 0.21 & $0.09-0.48$ & $<0.001$ \\
Cardiogenic shock & 5.84 & $2.20-15.53$ & $<0.001$ \\
$\begin{array}{l}\text { Multivariate Cox } \\
\text { Age } \geq 60 \text { yr }\end{array}$ & 1.78 & $0.78-4.05$ & 0.17 \\
$\quad \begin{array}{l}\text { Collateral circulation } \\
\text { Grade 2/3 }\end{array}$ & 0.55 & $0.23-1.33$ & 0.19 \\
Final flow TIMI Level 3 & 0.52 & $0.21-1.27$ & 0.15 \\
$\quad$ Cardiogenic shock & 4.07 & $1.40-11.83$ & 0.01 \\
\hline
\end{tabular}

Cl: confidence interval; HR: hazard ratio; TIMI: thrombolysis in myocardial infarction

Univariate Cox regression analysis revealed that age $\geq 60$ years, presence of CS, collateral circulation of Grade 2 or 3 , and final flow of TIMI Grade 3 correlated with overall mortality. Multivariate analysis showed that CS was the only independent predictor of overall mortality (hazard ratio 4.07, 95\% confidence interval [Cl] 1.40-11.83; $p=0.01$ ) (Table IV). Kaplan-Meier analysis showed that the estimated cumulative total survival rate of patients without CS was $51.3 \%$ and that of patients with CS was only $21.0 \%$ (Fig. 2).

\section{DISCUSSION}

AMI due to ULMCA disease is catastrophic; however, not all patients are able to undergo emergency coronary angiography for confirmation. For this reason, its true incidence may be unclear. In a study by Izumikawa et al, of 3,212 patients who received emergency coronary angiography, the IRA was confirmed to be the ULMCA in $72(2.2 \%)$ cases. ${ }^{(2)}$

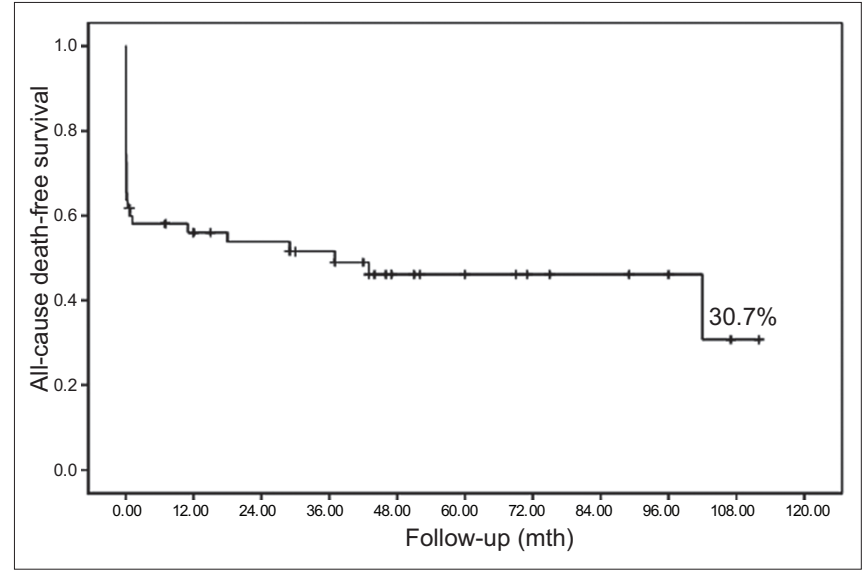

Fig. 1 Kaplan-Meier survival curve shows cumulative survival rates for all patients.

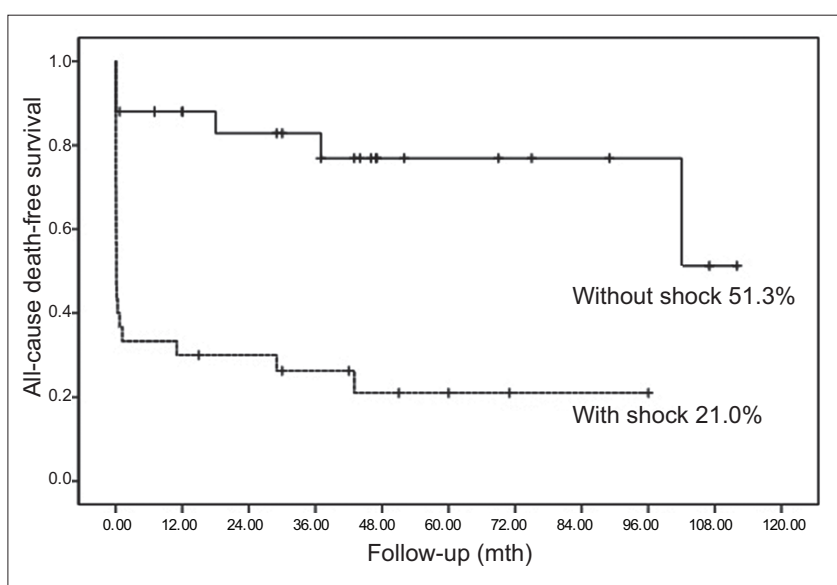

Fig. 2 Kaplan-Meier survival curve shows cumulative survival rates of patients with and without cardiogenic shock.

Among AMI patients receiving emergency $\mathrm{PCl}$, the ULMCA is the culprit lesion in $1.1 \%-2.2 \%{ }^{(4,5,13)}$ There is a high incidence of CS $(46 \%-78 \%)$ in these patients. ${ }^{(1-5)}$ Even after receiving successful reperfusion therapy, their acute-phase mortality was still as high at $39.7 \%-55 \%$. ${ }^{(1-5)}$ Previous studies focused mostly on predictors of acute-phase prognosis. A univariate analysis by Lee et al showed that self-recanalisation of the LMCA (TIMI Grade 2 or 3) was the determinant prognostic factor, ${ }^{(3)}$ while Iwasaki et al proposed 
that a dominant right coronary artery and well-developed collateral circulation might be the prognostic factor. ${ }^{(14)}$ In the present study, all patients had a dominant right coronary artery; the patients with small right coronary arteries might have had little opportunity to receive emergency coronary angiography. In a study by Hurtado et al, multivariate analysis showed that CS and incomplete revascularisation correlated with in-hospital mortality. ${ }^{(15)}$ In another study by Parma et al, multivariate analysis showed that $\mathrm{CS}$, age $\geq 75$ years and postoperative blood flow of TIMI Grade 3 correlated with the 30-day mortality rate. ${ }^{(5)}$ Similarly, our analysis suggests that CS (OR 5.86), well-developed collateral circulation (OR 0.14) and final flow of TIMI Grade 3 (OR 0.05) correlated with death during hospitalisation.

Few studies of patients with AMI due to ULMCA disease involved long-term follow-up. Sakai et al reported that the oneyear mortality rate of shock patients was significantly higher than that of patients without shock. ${ }^{(4)}$ In the study by Parma et al, shock, age $\geq 75$ years old, and final flow correlated with midterm follow-up results; Kaplan-Meier analysis showed the overall mid-term survival rate to be approximately $55.9 \%$, while the overall mid-term survival rate of patients with CS was 33.8\%. ${ }^{(5)}$ In Izumikawa et al's study of the long-term prognosis of LMCA occlusion patients after emergency $\mathrm{PCl}$, Kaplan-Meier analysis showed the total cumulative survival rate during follow-up to be $26.2 \%$ and that of shock patients to be $21.1 \%$. ${ }^{(2)}$ The results of the current study were similar: the overall mortality rate was $52.7 \%$ ( $n=29)$, while the total cumulative survival rate for all patients was $30.7 \%$ and that of patients with CS was only $21.0 \%$, suggesting a poor long-term prognosis for patients with CS.

In these prior studies, the Kaplan-Meier survival curves tended to be flat during mid- or long-term follow-up. ${ }^{(2,5)}$ Both Izumikawa et al and Parma et al proposed that the mid- and longterm prognosis of surviving patients might be relatively good. ${ }^{(2,5)}$ Similarly, Gagnor et al also reported that the rate of adverse events in patients after discharge was low. ${ }^{(6)}$ However, the Kaplan-Meier survival curve did not show similar results in the present study. This may be related to differences in follow-up time. In the study by Parma et al, follow-up time was $15.8 \pm 10.9$ months, with a median of only 14 months. ${ }^{(5)}$ The follow-up times of the studies carried out by Izumikawa et al and Gagnor at al were also only $1.7 \pm 2.9$ years and $504 \pm 653$ days, respectively, ${ }^{(2,6)}$ which was substantially shorter than the follow-up time in the current study, which was $44.6 \pm 31.3$ (median 60) months.

Previous studies have also shown that acute LMCA occlusion may lead to ST-segment elevation in the anterior wall as well as widespread ST-segment depression. Marso et al reported that, among 34 cases, there were 24 cases of ST-segment elevation. ${ }^{(1)}$ In Hurtado et al's study, STEMI only accounted for $59 \%$ of cases. ${ }^{(15)}$ However, in studies by Lee et al and Parma et al, all enrolled patients had STEMI. ${ }^{(3,5)}$ As Iwasaki et al indicated, variations in ECG manifestation are related to differences in coronary artery dominance and collateral circulation. ${ }^{(14)}$ In addition, they may also be related to differences in indications for emergency angiography in each study. Kim et al reported in their study that the proportion of STEMI among patients with CS was higher than in patients without CS. ${ }^{(16)}$ In our study, however, NSTEMI accounted for $14.5 \%$ of all cases and the rate of occurrence did not differ between the groups that survived and did not survive hospitalisation.

The optimal revascularisation strategy should be decided by a heart team that includes an interventional cardiologist and a cardiac surgeon. For the majority of patients with AMI due to ULMCA disease who suffer from severe CS, Iwasaki et al indicated that thrombolytic therapy could not produce satisfactory reperfusion and that emergency $\mathrm{PCl}$ should be the preferred treatment; ${ }^{(14)}$ if $\mathrm{PCl}$ fails, emergency CABG may be considered. In a study comparing outcomes after percutaneous or surgical revascularisation of ULMCA-related AMI by Grundeken et al, the 30-day mortality rates of the $\mathrm{PCl}$ and $\mathrm{CABG}$ groups were $64 \%$ and $24 \%$, respectively. ${ }^{(17)}$ However, in Grundeken et al's study, there was an obvious bias regarding the selection of revascularisation strategy: for patients with TIMI Grade 0 or 1 in angiography, $\mathrm{PCl}$ was preferred over CABG. ${ }^{(17)}$ The 2011 guideline for $\mathrm{PCl}$ from the American College of Cardiology Foundation (ACCF), American Heart Association (AHA), and Society for Cardiovascular Angiography and Interventions also pointed out that for STEMI in which distal coronary flow was TIMI Grade $<3$, PCl can be performed more rapidly and safely than CABG (class Ila recommendation). ${ }^{(18)}$ Marso et al reported that the mortality during hospitalisation in the balloon angioplasty-only group (70\%) and the stenting group (35\%) differed significantly, proposing that stent implantation could improve the prognosis. ${ }^{(1)}$ In a meta-analysis by $\mathrm{Vis}$ et $\mathrm{al}^{\left({ }^{(19)}\right.}$ the 30-day mortality of patients receiving drugeluting stent (DES) implantation was zero in the group without CS. In a study by Lee et al that studied 62 AMI patients with ULMCA lesions and DES implantation, DES was found to be safe and feasible. ${ }^{(20)}$ In the present study, except for two patients who died immediately after angiography and two CABG patients, 51 patients received emergency $\mathrm{PCl}$ and $32(71.1 \%)$ of the 45 stents were DES implantation. PCI with DES implantation should be the primary modality in these patients, with CABG used for 'bail-out' situations or when $\mathrm{PCl}$ is deemed not technically feasible.

In the present study, $94.5 \%$ of the patients received IABP implantation. The latest IABP in cardiogenic shock II study did not support the use of routine IABP implantation in CS patients receiving early revascularisation. ${ }^{(21)}$ However, as recommended in the 2013 ACCF/AHA STEMI guideline, the use of IABP counterpulsation can be useful in patients with CS after STEMI who do not quickly stabilise with pharmacological therapy (Class Ila recommendation). ${ }^{(22)}$ For emergency LMCA interventions, especially in patients with CS as a complication, IABP implantation may improve cardiac function and coronary perfusion. Parma et al also strongly recommended left ventricular assistance devices for these patients. ${ }^{(5)}$ In addition, although there has been no supporting evidence, prophylactic implantation of IABP may be suitable for some patients who do not develop CS before revascularisation. It may help to prevent a sharp haemodynamic deterioration in a short period of time due to reperfusion injury after rapid restoration of blood flow, causing patients to lose the opportunity for further treatment. 
The present study had its limitations. Firstly, due to the small sample size, it had a reduced power to identify predictors. Therefore, a multicentre registry study may be required in the future. Secondly, due to the low incidence of AMI due to ULMCA disease and the critical clinical conditions of these patients, it was difficult to perform a prospective, randomised study to explore the differences between various methods of revascularisation (e.g. CABG vs. $\mathrm{PCl}$, bare-metal stents vs. DES) and between different haemodynamic support techniques (e.g. whether prophylactic IABP implantation or other cardiopulmonary assist devices are needed). Hence, we conducted a retrospective observational study. Thirdly, ten patients died before they could receive an echocardiography examination even though the LVEF of these patients might have been severely impaired, resulting in possible bias when the impact of LVEF on mortality was analysed.

In conclusion, the present study showed a high incidence of CS and mortality in AMI patients resulting from ULMCA lesions. CS, poor collateral blood flow and failure to restore final flow TIMI Grade 3 correlated with death during hospitalisation. CS was the only predictor of long-term overall mortality in these patients.

\section{REFERENCES}

1. Marso SP, Steg G, Plokker T, et al. Catheter-based reperfusion of unprotected left main stenosis during an acute myocardial infarction (the ULTIMA experience). Unprotected Left Main Trunk Intervention Multicenter Assessment. Am J Cardiol 1999; 83:1513-7.

2. Izumikawa T, Sakamoto S, Takeshita S, Takahashi A, Saito S. Outcomes of primary percutaneous coronary intervention for acute myocardial infarction with unprotected left main coronary artery occlusion. Catheter Cardiovasc Interv 2012; 79:1111-6

3. Lee SW, Hong MK, Lee CW, et al. Early and late clinical outcomes after primary stenting of the unprotected left main coronary artery stenosis in the setting of acute myocardial infarction. Int J Cardiol 2004; 97:73-6.

4. Sakai K, Nakagawa Y, Kimura T, et al. Primary angioplasty of unprotected left main coronary artery for acute anterolateral myocardial infarction. J Invasive Cardiol 2004; 16:621-5.

5. Parma A, Fiorilli R, DE Felice F, et al. Early and mid-term clinical outcome of emergency $\mathrm{PCl}$ in patients with STEMI due to unprotected left main coronary artery disease. J Interv Cardiol 2012; 25:215-22.

6. Gagnor A, Tomassini F, Romagnoli E, et al. Primary angioplasty in STelevation myocardial infarction due to unprotected left-main coronary disease in a high-volume catheterization center without on-site surgery facilities: immediate and medium-term outcome: the STEMI-Placet Registry. J Invasive Cardiol 2012; 24:645-9.

7. Thygesen K, Alpert JS, Jaffe AS, et al; ESC Committee for Practice Guidelines (CPG). Third universal definition of myocardial infarction. Eur Heart J 2012; 33:2551-67.

8. Chesebro JH, Knatterud G, Roberts R, et al. Thrombolysis in Myocardial Infarction (TIMI) Trial, Phase I: A comparison between intravenous tissue plasminogen activator and intravenous streptokinase. Clinical findings through hospital discharge. Circulation 1987; 76:142-54.

9. Rentrop KP, Cohen M, Blanke H, Phillips RA. Changes in collateral channel filling immediately after controlled coronary artery occlusion by an angioplasty balloon in human subjects. J Am Coll Cardiol 1985; 5:587-92.

10. Puricel S, Adorjan $\mathrm{P}$, Oberhänsli $\mathrm{M}$, et al. Clinical outcomes after $\mathrm{PCI}$ for acute coronary syndrome in unprotected left main coronary artery disease: insights from the Swiss Acute Left Main Coronary Vessel Percutaneous Management (SALVage) study. Eurolntervention 2011; 7:697-704.

11. Gao RL, Xu B, Chen JL, et al; Chinese Registry of Unprotected Left Main Coronary Artery Stenting Investigators. Prognosis of unprotected left main coronary artery stenting and the factors affecting the outcomes in Chinese. Chin Med J (Engl) 2006; 119:14-20.

12. Hochman JS, Sleeper LA, Webb JG, et al. Early revascularization in acute myocardial infarction complicated by cardiogenic shock. SHOCK investigators. Should We Emergently Revascularize Occluded Coronaries for Cardiogenic Shock. New Engl J Med 1999; 341:625-34.

13. Shihara M, Tsutsui $H$, Tsuchihashi $M$, et al; Japanese Coronary Invention Study (JCIS) Group. In-hospital and one-year outcomes for patients undergoing percutaneous coronary intervention for acute myocardial infarction. Am J Cardiol 2002; 90:932-6.

14. Iwasaki K, Kusachi S, Hina K, et al. Acute left main coronary artery obstruction with myocardial infarction--reperfusion strategies, and the clinical and angiographic outcome. Jpn Circ J 1993; 57:891-7.

15. Hurtado J, Pinar Bermúdez E, Redondo B, et al. Emergency percutaneous coronary intervention in unprotected left main coronary arteries. Predictors of mortality and impact of cardiogenic shock. Rev Esp Cardiol 2009; 62:1118-24

16. Kim U, Park JS, Kang SW, et al; Korea Acute Myocardial Infarction Registry Investigators. Outcomes according to presentation with versus without cardiogenic shock in patients with left main coronary artery stenosis and acute myocardial infarction. Am J Cardiol 2012; 110:36-9.

17. Grundeken MJ, Vis MM, Beijk MA, et al. Clinical outcomes after percutaneous or surgical revascularisation of unprotected left main coronary artery-related acute myocardial infarction: a single-centre experience. Heart 2013; 99:690-9.

18. Levine GN, Bates ER, Blankenship JC, et al; American College of Cardiology Foundation; American Heart Association Task Force on Practice Guidelines; Society for Cardiovascular Angiography and Interventions. 2011 ACCF/AHA/SCAI Guideline for Percutaneous Coronary Intervention. A report of the American College of Cardiology Foundation/American Heart Association Task Force on Practice Guidelines and the Society for Cardiovascular Angiography and Interventions. J Am Coll Cardiol 2011; 58:e44-122.

19. Vis MM, Beijk MA, Grundeken MJ, et al. A systematic review and metaanalysis on primary percutaneous coronary intervention of an unprotected left main coronary artery culprit lesion in the setting of acute myocardial infarction. JACC Cardiovasc Interv 2013; 6:317-24.

20. Lee MS, Sillano D, Latib A, et al. Multicenter international registry of unprotected left main coronary artery percutaneous coronary intervention with drug-eluting stents in patients with myocardial infarction. Catheter Cardiovasc Interv 2009; 73:15-21.

21. Thiele H, Zeymer U, Neumann FJ, et al; Intraaortic Balloon Pump in cardiogenic shock II (IABP-SHOCK II) trial investigators. Intra-aortic balloon counterpulsation in acute myocardial infarction complicated by cardiogenic shock (IABP-SHOCK II): final 12 month results of a randomised, open-label trial. Lancet 2013; 382:1638-45.

22. O'Gara PT, Kushner FG, Ascheim DD, et al; American College of Cardiology Foundation/American Heart Association Task Force on Practice Guidelines. 2013 ACCF/AHA guideline for the management of ST-elevation myocardial infarction: a report of the American College of Cardiology Foundation/American Heart Association Task Force on Practice Guidelines. Circulation 2013; 127:e362-425. 